Original Research Article

\title{
A prospective comparative study to assess the efficacy and safety of sertraline and methylcobalin with pregabalin and methylcobalin in patients suffering with depression due to diabetic neuropathic pain
}

\author{
V. Sivasankari ${ }^{1 *}$, E. Manivannan ${ }^{1}$, S. P. Priyadarsini²
}

\begin{abstract}
${ }^{1}$ Department of Pharmacology, Vinayaka Mission's Kirupananda Variyar Medical College, Salem 636308,

Tamilnadu, India

${ }^{2}$ Department of Community

Medicine, Annapoorna Medical

College and Hospital, Salem

636308, Tamilnadu, India
\end{abstract}

Received: 28 September 2017

Accepted: 27 October 2017

*Correspondence to:

Dr. V. Sivasankari,

Email: drvsivasankari@

gmail.com

Copyright: (c) the author(s), publisher and licensee Medip Academy. This is an openaccess article distributed under the terms of the Creative Commons Attribution NonCommercial License, which permits unrestricted noncommercial use, distribution, and reproduction in any medium, provided the original work is properly cited.

\begin{abstract}
Background: Diabetic neuropathic pain produces mood swings thereby creating emotional disturbances ranging from mild anxiety to severe depression when the disease progresses for 10 years or more. The existing treatment includes Tricyclic antidepressants, Selective Serotonin Reuptake Inhibitors, anticonvulsants, Dual Reuptake Inhibitor antidepressant, topical agents like capsaicin, lignocaine, gabapentin. Yet the psychological component has to be treated with the antidepressants. Even though SSRI's like sertraline has shown some promising results as analgesic but could works better as an antidepressant. Hence, this work emphasizes some promising role of sertraline as an adjuvant to methylcobalin and other medications in the management of depression due to diabetic neuropathic pain.

Methods: A total of 100 consecutive patients of both sex between the age group of 18-65 years with painful diabetic neuropathic pain with signs and symptoms depression were recruited and randomized into two groups. Statistical methods: Data were tabulated, and results were analyzed. Chi-square test was used to analyze demographic data of the study population. Depressive score was analyzed at baseline and 12th week by using Student's t-test and Analys is of Co variance. A p value of $<0.05$ was considered as statistically significant.

Results: Group I patients showed an improvement of symptomatology where the number of patients shifted from mild to minimal depression. This is critically less in Group II.

Conclusions: The combination of sertraline with methylcobalin showed a promising outcome with improvement of symptoms of painful diabetic neuropathic pain in Indian patients.
\end{abstract}

Keywords: Antidepressants, Diabetes mellitus, Diabetic neuropathic pain, Depression, Methylcobalin, Sertraline

\section{INTRODUCTION}

Diabetic peripheral neuropathy [DPN] is one of the common complication of uncontrolled diabetes which affects the lower extremities damaging the small nerve fibres followed by the larger one. ${ }^{1}$ The pain which is persistent for many hours in a day will produces a profound effect upon the mood and personality changes causing profound depression, fatigue, anxiety. ${ }^{2}$
The risk factors associated with DPN includes poor glycemic control, dyslipedemia, prolonged disease process, patients with high BMI, albuminuria. Hence, the secondary prevention should be focused on good glycemic control in addition to insulin if necessary,statins to treat dyslipedemia, lifestyle management for obesity, ACE inhibitors for preventing albuminuria. ${ }^{3}$

Most of the patients have been treated with Tricyclic Antidepressants [TCAs], Selective Serotonin Reuptake 
Inhibitors [SSRIs], anticonvulsants, local anaesthetics, opioids, topical agents, miscellaneous drugs, alternative therapies. ${ }^{4}$ The symptoms of depression prevail with treatment of pregabalin, gabapentin, tramadol, methadone, methylcobalin, clonidine, lignocaine patch. ${ }^{5}$ Hence, addition of a SSRI could possibly an answer for the ongoing depression due to DPN. The specific advantages over tricyclic antidepressants are inhibition of presynaptic reuptake of serotonin, less autonomic side effects. ${ }^{6,7}$ Even SSRIs like fluvoxetine, paroxetine, citalopram has shown mixed results in the treatment of DPN with few studies had demonstrated the role of antidepressants in the treatment of DPN. ${ }^{8,9}$ Since the clinical experience of using SSRI is minimal, an attempt was made to found out the efficacy of sertraline [SRT] in combination with methylcobalin [MC]. This combination was compared with pregabalin [PG] and methylcobalin in DPN patients.

The study was conducted with strict adherence to the protocol. The aim of the study was to compare the efficacy and safety of sertraline and methylcobalin with pregabalin and methylcobalin in the treatment of associated depression due to diabetic neuropathic pain.

\section{METHODS}

This prospective, comparative study was conducted among diabetic patients attending the Diabetic clinic, Department of Medicine at a tertiary care teaching hospital, VMKVMC, Salem and Praveen diabetic clinic, Salem for a period of 6 months between June 2016 to Dec 2016.

\section{Primary outcome}

A mild improvement in the symptomatology of depression scale.

\section{Secondary outcome}

Adverse events that was reported by the patient or the physician.

\section{Inclusion criteria}

Patients of both sexes between the age group of 18-65 with painful neuropathic pain with signs and symptoms of minimal to moderate depression were recruited for the study.

This study included the outpatients whom the protocol was explained, and informed consent was obtained.

\section{Exclusion criteria}

1. Diabetic patients with suicidal tendencies, bipolar disorder, substance abuse, treatment with other antidepressants and antianxiety drugs were excluded.
2. Hypersensitivity reactions to sertraline, methylcobalin, pregabalin were excluded from the study.

A total of 100 consecutive patients who fulfilled the inclusion criteria were recruited for the study and randomized into 2 groups based on odd and even batches. Group I patients were given sertraline 50mg twice daily with $1500 \mu \mathrm{g}$ methylcobalin once daily and Group II were given pregabalin $75 \mathrm{mg}$ thrice daily with methylcobalin $1500 \mu \mathrm{g}$ once daily for a period of 12 weeks. The antidiabetic medications were taken by the patients regularly which doesn't interfere by the study medication, thereby starting at baseline, the demographic details were recorded along with the routine blood investigations of the patients which includes Fasting Blood Sugar [FBS], Post Prandial Blood Sugar [PPBS], HbA1C, lipid profile, urea, creatinine, liver function test, urine routine test which was repeated again at the end of the study period.

Patients were screened during visit 1 . The efficacy and safety were as sessed after 3 months of treatment. The Beck depression inventory scale was used to assess the degree of depression. The total score is compared to a key to determine the severity of depression. The questionnaire consists of 21 groups of statements with each answer being scored on a scale value of 0 to 3 . Scores of 0-9 was marked as minimal depression, 9-18 mild depression, 19-29 as moderate depression and $>30$ as severe depression. Higher scores indicate more depression.

\section{Statistical analysis}

Data were tabulated, and statistical analysis was done by using Epi info software. Results were expressed as frequencies and percentages and Chi-square test was used to compare the demographic data and laboratory parameters of the study population. Beck Inventory Depressive score was analyzed at baseline and $12^{\text {th }}$ week by using Student's t-test and comparison of means between the two groups were analyzed by using ANOVA. A $p$ value of $<0.05$ was considered as statistically significant.

\section{RESULTS}

The age and gender wise distribution of both groups are depicted in Table 1.

By randomization $74 \%$ were males in group I with $68 \%$ were males in group II with the male: female ratio being 2:1. The mean age was 48.2 in sertraline group and 49.8 years in pregabalin group. Majority of the patient were in the age group of 41 to 60 years. No statistical significance was found between these groups.

Table 2 showed the sociodemographic data of two groups. About $30 \%$ of patients were as sociated with hypertension, $8 \%$ associated with bronchial asthma and $8 \%$ with chronic obstructive pulmonary disease (COPD) in sertraline group 
and $34 \%$ were with hypertension, $10 \%$ had bronchial asthma and $6 \%$ had COPD in pregabalin group. Among the total patients $26 \%$ were smokers and $6 \%$ alcoholic and $32 \%$ of patients were both smokers and alcoholics in group I compared to $34 \%$ were smokers, $22 \%$ were alcoholic and $24 \%$ were both smokers and alcoholic in group II. This data correlate with degree of illness.

Table 1: Age and sex wise distribution of the study population.

\begin{tabular}{|c|c|c|c|c|c|}
\hline \multirow{2}{*}{$\begin{array}{l}\text { Age } \\
\text { group } \\
\text { in } \\
\text { years }\end{array}$} & \multicolumn{2}{|c|}{$\begin{array}{l}\text { Group I } \\
\text { [SRT+MC] } \\
(n=50)\end{array}$} & \multicolumn{2}{|c|}{$\begin{array}{l}\text { Group II } \\
{[\mathrm{GP}+\mathrm{MC}]} \\
(\mathbf{n}=\mathbf{5 0})\end{array}$} & \multirow[t]{2}{*}{$\begin{array}{l}\mathbf{P} \\
\text { value* }\end{array}$} \\
\hline & Male & Female & Male & Female & \\
\hline $20-30$ & $\begin{array}{l}5 \\
(10 \%)\end{array}$ & $\begin{array}{l}3 \\
(6 \%)\end{array}$ & $\begin{array}{l}4 \\
(8 \%)\end{array}$ & $\begin{array}{l}2 \\
(4 \%)\end{array}$ & \multirow{7}{*}{0.4} \\
\hline $31-40$ & $\begin{array}{l}11 \\
(22 \%)\end{array}$ & $\begin{array}{l}4 \\
(8 \%)\end{array}$ & $\begin{array}{l}13 \\
(26 \%)\end{array}$ & $\begin{array}{l}5 \\
(10 \%)\end{array}$ & \\
\hline $41-50$ & $\begin{array}{l}6 \\
(12 \%)\end{array}$ & $\begin{array}{l}2 \\
(4 \%)\end{array}$ & $\begin{array}{l}2 \\
(4 \%)\end{array}$ & $\begin{array}{l}3 \\
(6 \%)\end{array}$ & \\
\hline $51-60$ & $\begin{array}{l}14 \\
(32 \%)\end{array}$ & $\begin{array}{l}2 \\
(6 \%)\end{array}$ & $\begin{array}{l}13 \\
(26 \%)\end{array}$ & $\begin{array}{l}4 \\
(8 \%)\end{array}$ & \\
\hline$>60$ & $1(2 \%)$ & $2(4 \%)$ & $2(4 \%)$ & $2(4 \%)$ & \\
\hline Total & $\begin{array}{l}37 \\
(74 \%)\end{array}$ & $\begin{array}{l}13 \\
(26 \%)\end{array}$ & $\begin{array}{l}34 \\
(68 \%)\end{array}$ & $\begin{array}{l}16 \\
(32 \%)\end{array}$ & \\
\hline $\begin{array}{l}\text { Mean } \\
\text { age }\end{array}$ & \multicolumn{2}{|c|}{$48.2 \pm 1.2$} & \multicolumn{2}{|c|}{$49.8 \pm 4.2$} & \\
\hline
\end{tabular}

*P value derived by applying chi-square test
Table 2: Socio demographic data of the study population.

\begin{tabular}{|lll|}
\hline Parameters & $\begin{array}{l}\text { Gp-I } \\
\text { [SRT+MC] } \\
\text { No of cases }\end{array}$ & $\begin{array}{l}\text { Gp-II } \\
\text { [PG+MC] } \\
\text { No of cases }\end{array}$ \\
\hline Co-morbidity & & \\
\hline 1. Hypertension & $15(30 \%)$ & $17(34 \%)$ \\
\hline 2. Asthma & $4(8 \%)$ & $5(10 \%)$ \\
\hline 3. COPD & $4(8 \%)$ & $3(6 \%)$ \\
\hline Social habits & & \\
\hline 1. Smokers & $13(26 \%)$ & $7(34 \%)$ \\
\hline 2. Alcoholics & $3(6 \%)$ & $11(22 \%)$ \\
\hline 3. Both & $16(32 \%)$ & $12(24 \%)$ \\
\hline Duration of DPN & $4.08 y r s \pm 4.6$ & $3.87 \mathrm{yrs} \pm 3.16$ \\
\hline Duration of diabetes & $11.5 y$ rs \pm 2.6 & $10.2 \mathrm{yrs} \pm 3.7$ \\
\hline Notes: $\mathrm{n}=$ no of subjects and $\%=$ percentage \\
\hline
\end{tabular}

The average duration of diabetes was 11.5 years in group I and 10.2 years in group II. The duration of the symptoms of diabetic peripheral neuropathy was 4.08 years in group I when compared to 3.87 years in group II.

Table 3 showed the blood sugar level and lipid profile of Group I and Group II patients. The baseline readings with the mean FBS was $148 \mathrm{mg} / \mathrm{dl}$ in group I and $106 \mathrm{mg} / \mathrm{dl}$ in group II. The mean PPBS were $214 \mathrm{mg} / \mathrm{dl}$ and $188 \mathrm{mg} / \mathrm{dl}$ in group II. Also the Table 3 showed lipid profile readings.

Table 3: Blood sugar level and lipid profile of Group I and Group II patients.

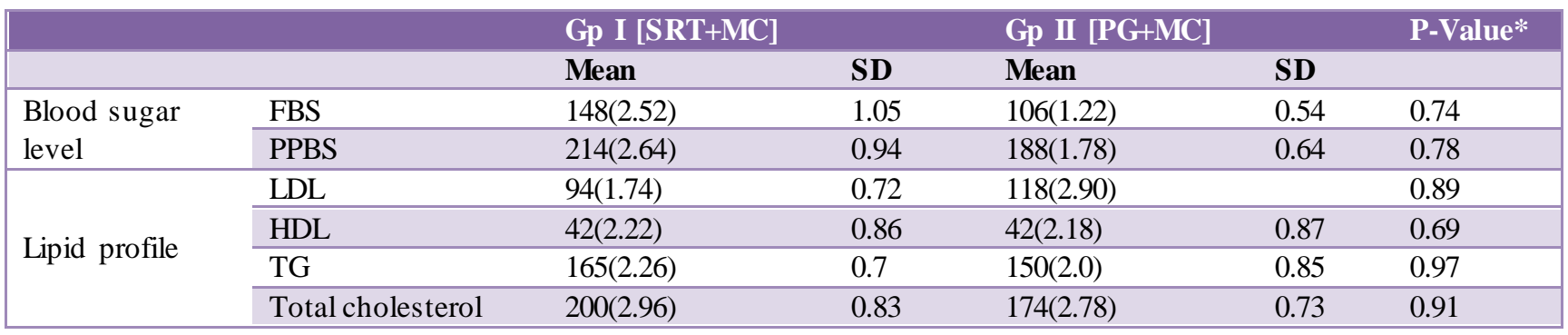

FBS-fasting blood sugar; PPBS-post prandial blood sugar; LDL-low-density lipoprotein;

HDL-high-density lipoprotein; TG-trigly cerides; *P value derived by using chi-square test not significant. SD - Standard deviation

As far as the distribution of the pain was concerned $90 \%$ involvement was noticed in lower extremities when compared to upper extremities. The common symptoms noticed in our study subjects were numbness $(60 \%)$ followed by aching pain (22\%), pin pricking (10\%) and burning pain. Analysis was done on each patient by proper scoring just before the start of the treatment and after 12 weeks of drug treatment in both the groups.

By analyzing the frequency table, Group I patients showed an improvement of symptomatology where the number of patients shifted from mild to minimal depression. This is critically less in Group II.
Table 4: Comparison of degree of depression between two groups - frequency table.

\begin{tabular}{|c|c|c|c|c|}
\hline \multirow[b]{2}{*}{$\begin{array}{l}\text { Para- } \\
\text { meter }\end{array}$} & \multicolumn{2}{|c|}{ Gp I [SRT+MC] } & \multicolumn{2}{|c|}{ Gp I [PG+MC] } \\
\hline & $\begin{array}{l}\text { At baseline } \\
\text { frequency } \\
\mathrm{n}=\mathbf{5 0} \\
(\%)\end{array}$ & $\begin{array}{l}\text { At } 12^{\text {th }} \\
\text { week } \\
n=50 \\
(\%)\end{array}$ & $\begin{array}{l}\text { At } \\
\text { Baseline } \\
\mathbf{n}=50 \\
(\%)\end{array}$ & $\begin{array}{l}\text { At } 12^{\text {th }} \\
\text { week } \\
n=50 \\
(\%)\end{array}$ \\
\hline $\begin{array}{l}\text { Minimal } \\
\text { depression }\end{array}$ & $\begin{array}{l}35 \\
(70 \%)\end{array}$ & $\begin{array}{l}49 \\
(98 \%)\end{array}$ & $\begin{array}{l}37 \\
(74 \%)\end{array}$ & $\begin{array}{l}41 \\
(82 \%)\end{array}$ \\
\hline Mild & $\begin{array}{l}15 \\
(30 \%)\end{array}$ & $\begin{array}{l}1 \\
(2 \%)\end{array}$ & $\begin{array}{l}13 \\
(26 \%)\end{array}$ & $\begin{array}{l}9 \\
(18 \%)\end{array}$ \\
\hline
\end{tabular}

$\mathrm{n}=$ no of subjects participated in the study and $\%=$ percentage 
Table 5: Beck depression inventory scale.

\begin{tabular}{|c|c|c|c|c|c|}
\hline \multirow{2}{*}{$\begin{array}{l}\text { Parameter } \\
\text { depressive } \\
\text { symptom } \\
\text { score }\end{array}$} & \multicolumn{2}{|c|}{$\begin{array}{l}\text { Group I } \\
\text { [SRT+MC] }\end{array}$} & \multicolumn{2}{|c|}{$\begin{array}{l}\text { Group II } \\
\text { [PG+MC] }\end{array}$} & \multirow{2}{*}{$\begin{array}{l}\text { P value } \\
\text { *(by } \\
\text { applying } \\
\text { T test) }\end{array}$} \\
\hline & Mean & SD & Mean & SD & \\
\hline Baseline & 10.04 & 4.458 & 9.92 & 6.92 & 0.001 \\
\hline $\begin{array}{l}\text { At } 12^{\text {th }} \\
\text { week }\end{array}$ & 8.80 & 4.314 & 4.179 & 3.539 & 0.001 \\
\hline $\begin{array}{l}\text { P value (by } \\
\text { applying } \\
\text { ANOVA) }\end{array}$ & 0.001 & & 0.001 & & \\
\hline
\end{tabular}

The symptom score showed positivity in the symptoms of depression along with DPN in sertraline group and majority of patients were shifted from mild to minimal depression.

Table 6: Occurrence of various adverse events among the two groups of patients.

\begin{tabular}{|lll|}
\hline Parameter & $\begin{array}{l}\text { Group I } \\
\text { [SRT+MC] } \\
(\mathbf{n = 5 0})\end{array}$ & $\begin{array}{l}\text { Group II } \\
{[\mathbf{P G + M C ]}} \\
(\mathbf{n = 5 0})\end{array}$ \\
\hline Adverse events & & 2 \\
\hline Dizzines & 4 & - \\
\hline Insomnia & 2 & - \\
\hline Fatigue & 4 & 2 \\
\hline Drowsines & 2 & 1 \\
\hline Headache & - & 3 \\
\hline Sedation & 3 & - \\
\hline Agitation & 2 & 2 \\
\hline Nausea & 1 & - \\
\hline Constipation & 1 & \\
\hline n= no of subjects; ADR-adverse drug reactions
\end{tabular}

As far as the adverse effects concerned they were categorized and depicted in Table 6 . There were no major adverse events reported in both the groups and mild adverse reactions were treated symptomatically.

\section{DISCUSSION}

A total of 100 patients diagnosed as Type II DM with symptomatology of depression were divided randomly in two groups. Group I received sertraline with methylcobalin and group II received pregabalin with methylcobalin. The demographic data was recorded with male and female ratio being 2:1. The mean ages of both the groups were $48 \mathrm{yrs}$ with the majority of the patients lie between 40 to 60years. This is correlating with many studies like Kiani et al, and Barbosa et al. ${ }^{10,11}$ Our study showed the development of DPN in type II diabetic patients was around 4 years with the total duration of illness being 11 years. The clinical data relating the effectiveness of the FDC of pregabalin with methylcobalin was established in studies like PRECISE, PRECISE II and concluded that the combinations were safe thereby reducing the symptoms of DPN. ${ }^{2}$ There is a paucity of literature review about the FDC of sertraline with methylcobalin.

An animal study by Talha Jawaid et al showed a promising result with sertraline in the treatment of DPN with co morbid depressed rats. ${ }^{12}$ Goodnick PJ et al, has showed a promising result in 8 patients with a significant improvement in pain. These evidences support the utilization of sertraline in depressed diabetic patients due to peripheral neuropathy. ${ }^{13}$ The Cochrane collaboration suggested high quality studies to analyze the effect of sertraline as an alternative in the management of DPN. ${ }^{14,15}$

Treatment of depression due to neuropathic pain will be beneficial by perfect employment, sound sleep, and higher degree of social functioning. Nicola Torrance et al explained that poor Quality of Life [QOL] is associated with chronic Painful DPN. ${ }^{16}$

The Beck Depression Inventory is common scale to measure the severity of depression. We measured our patients at the baseline and after 12 weeks and found out that there is a marginal improvement of depression due to DPN. More over the patient's acceptability is far better with sertraline as minimal side effects were noticed at the end of the study. Further studies have to be carried out in large scales in different ethnic population to find out the effectiveness of sertraline over other SSRI in the treatment of depressed DPN patients.

The results of this study had important limitations such as it was an open label study with small sample size, and chances of some missing dates.

\section{CONCLUSION}

Treatment of DPN is challenging and the spectrum varies. Early diagnosis by proper history, clinical examination, and available simple instruments will help in prevention of morbidity of the patients. Good glycemic control, appropriate analgesics, prevention of complications such as foot ulcer is recommended in daily practice.

\section{ACKNOWLEDGEMENTS}

Authors would like to thank the study participants and technical staffs who helped to complete the research success fully.

Funding: No funding sources

Conflict of interest: None declared

Ethical approval: The study was approved by the Institutional Ethics Committee of VMKVMC, Salem

\section{REFERENCES}

1. Halawa MR, Karawagh A, Zeidan A, Mahmoud AE, Sakr M, Hegazy A, painful diabetic peripheral 
neuropathy study group. Prevalence of painful diabetic peripheral neuropathy among patients suffering from diabetes mellitus in Saudi Arabia. Current medical research and opinion. 2010 Feb 1;26(2):337-43.

2. Dongre TU, Swami OC. Sustained-release pregabalin with methylcobalamin in neuropathic pain: an Indian real-life experience, University of Michigan, International J of General Medicine. 2013;6:413-7.

3. Khan SE. Cooper ME, Del prato S. pathophysiology and treatment of type II Diabetes; prospectives on the past, present and future. Lancet. 2013;383:1068-83.

4. De Groot $M$, Kushnick M, Doyle T, Merrill J, McGlynn M, Shubrook J, et al. Depression among adults with diabetes: prevalence, impact, and treatment options. Diabetes Spectrum. 2010 Jan 21;23(1):15-8.

5. Tesfaye s. Selvarajah D. advances in epidemiology, pathogenesis and management of diabetic peripheral neuropathy. Diabeto Metab Res. Rev 2012Feb;28(1):8-14.

6. Aaron IV, Casellini CM. Guidelines in the management of diabetic nerve pain: clinical utility of pregabalin. Diabetes Metab Syndr Obes. 2013;6:5778.

7. Saxena AK, Nath S, Kapoor R. Diabetic Peripheral Neuropathy: Current Concepts and Future Perspectives. Journal of Endocrinology and Diabetes. 2015;2(5):1-8.

8. Snyder MJ, Gibbs LM, Lindsay TJ. Treating Painful Diabetic Peripheral Neuropathy: An Update. American family physician. 2016 Aug;94(3):227-34.

9. Ziegler D, Fonseca V. From guideline to patient: a review of recent recommendations for pharmacotherapy of painful diabetic neuropathy. J of Diabetes and its Complications. 2015 Feb 28;29(1):146-56.
10. Kiani J, Azizkhani H, Kosarifard S. The prevalence and associated risk factors of peripheral diabetic neuropathy in Hamedan, Iran. Archives of Iranian Medicine. 2013 Jan 1;16(1):17.

11. Barbosa AP, Medina JL, Ramos EP, Barros HP. Prevalence and risk factors of clinical diabetic polyneuropathy in a Portuguese primary health care population Diabetes metabolism. 2001 Sep;(4 pt 1):496-502.

12. Jawaid T, Shakya AK, Kamal M, Hussain S. Amitriptyline and sertraline in diabetic neuropathy: a comparative view. International J of Health Research. 2008;1(2):73-8.

13. Goodnick PJ, Jimenez I, Kumar A. Sertraline in diabetic neuropathy: preliminary results. Ann Clin Psychiatry. 1997 Dec; 9(4):255-7.

14. Casandra. J. Rosenberg treatment of painful diabetic peripheral neuropathy prosthetics and orthotics International. 2015;39(1):17-25.

15. Amy M. Barret Epidemiology, public health burden and treatment of diabetic peripheral Neuropathic pain: A Review, American Academy of Pain Medicine. 2006;8:50-62.

16. Torrance N, Ferguson JA, Afolabi E, Bennett MI, Serpell MG, Dunn KM, et al. Neuropathic pain in the community: more under-treated than refractory? PAIN®. 2013 May 31;154(5):690-9.

Cite this article as: Sivasankari V, Manivannan E, Priyadarsini SP. A prospective comparative study to assess the efficacy and safety of sertraline and methylcobalin with pregabalin and methylcobalin in patients suffering with depression due to diabetic neuropathic pain. Int J Basic Clin Pharmacol 2017;6:2871-5. 